\title{
Editorial: The Philosophy of Intellectual History and Conceptual Change
}

Intellectual history, understood as the study of thinkers, ideas and thinking patterns in history, is probably the most interdisciplinary form of history writing that there is. An intellectual historian must be able to comprehend and study a great number of disciplines and contexts, even if one is not necessarily committed to the existence of unit ideas that traverse from context to context. However, because of its broad scope, intellectual history can sometimes seem shapeless and borderless.

Interdisciplinarity and elusive boundaries would not be a problem if the basic intellectual unit(s) of intellectual history were explicit and the method by which to study them precise. Clarity regarding the basic unit of analysis and method of study would bring rigour and coherence to its practice. The intellectual historian would be able to stick to her disciplinary commitments and delineate the existence and the functions of these units in other disciplines and contexts from this specific methodological vantage point.

It is thus unsurprising that there has been a productive debate about what these basic intellectual units should be and how intellectual history should be studied at large. It has been asked whether these units to be studied are concepts, ideas, some other larger thought complexes, sentences, other linguistic entities or something else entirely. And if they are, say, concepts, should they be conceived of as Platonic, linguistic, mental or some other kinds of entities? Further questions include the following: What defines when a concept is the same and when it is different? How much change is allowed for two conceptual instantiations of the 'same' intellectual unit in a historical trajectory? And so on.

Naturally, there have also been powerful and insightful expressions of what the study of intellectual history consists in. Arguably one of the most famous is Arthur Lovejoy's project of unit ideas. ${ }^{1}$ According to it, unit ideas can be identified in their basic form and in combinations in innumerable frameworks.

1 A. Lovejoy, The Great Chain of Being: A Study of the History of an Idea (Cambridge, MA: Harvard University Press, 1936); Essays in the History of Ideas (Baltimore: John Hopkins Press, 1948). 
Quentin Skinner sought to question this postulation as a form of historical insensitivity leading to distortion rather than to understanding. ${ }^{2}$ He suggested that the history of thinking must be deeply contextual and identify the intentions that lie behind historical agents' rhetorical interventions.

The current issue is a thematic forum debate on the philosophy of intellectual history and conceptual change which contributes to the ongoing reflection on the foundations of intellectual history and conceptual history. The foundational event of this issue dates back to the conference Conceptual Change in History in September 22-24, 2016 in Helsinki, which was co-organised by The Centre for Philosophical Studies of History and the project "Reinventing the foundations of the European Legal Culture 1934-1964".

Although an observation about the interdisciplinary nature of intellectual history was, indeed, the key rationale that led to this conference, this observation stems from metalevel reflection. It is notable that the history of concepts is studied in a number of different fields and scholarly traditions that communicate with each other only satisfactorily at best: Lovejoyian history of ideas, the Cambridge school of intellectual history, German Begriffsgeschichte, the cognitive history and philosophy of science, legal history, the history of philosophy, the history of science and so on. Further, cognitive science, philosophy of language, philosophy of mind and theories of education have constructed rival theories of concepts which can, in principle, be used to make sense of conceptual change and the history of concepts. The aim of the conference was to bring together scholars who study conceptual change and the history of thinking but who represent different fields, in order to open dialogues between them.

The forum debate presents some results of the conference (Straumann, Kaukua and Lähteenmäki, Bloch-Mullins). Two papers of this issue were submitted directly to the journal (Blau, Alexander). Benjamin Straumann defends an account of concepts inspired by Frege's philosophy against "the historicist theory of concepts" whose insight stems from the later Wittgenstein. Straumann emphasises that his theory of concepts has two main virtues. Because of the relative independence of concepts from their contexts, his theory is able to account for conceptual stability. It also manages to explain the causal influence of concepts in society. Kaukua and Lähteenmäki similarly stress invariability in intellectual history. They focus on standards of conceptual change and ask how we can recognise that a conceptual change has occurred. They argue that conceptual change would be unintelligible without a commitment to some common non-textual standards, the shared "features of the world of

2 Q. Skinner, "Meaning and Understanding in the History of Ideas", History and Theory, 8 (1969), $36-38$. 
experience," between the historian and historical agents. Bloch-Mullins in turn concentrates on the dynamic aspects of conceptual change in her paper. She develops an account of conceptual change which stresses the 'forward-looking' nature of concepts. A key feature of her account, illustrated by the conceptual change of 'synapse' in the history of biology, is the existing conceptual structure, or what she calls "conceptual taxonomy." It both conceptually facilitates and constrains new empirical phenomena discovered by scientists.

Adrian Blau's article is named "Meanings and Understandings in the History of Ideas" in reminiscence of Skinner's classic 1969 paper. Blau argues that there are four types of meaning and understanding in intellectual history (which explains the plural forms in the title). In particular, he wishes to draw our attention to a neglected meaning, which he calls 'extended meaning.' Extended meaning refers to the implications of what people say and write. Finally, James Alexander begins his paper with the claim that there are three ways to write history ideas: impose one's own idea on history for unity, abstract one particular idea for clarity, or indicate what ideas meant to historical agents thereby maintaining plurality. His focus is on the notion of the Enlightenment, which he understands as something that is supposed to have happened in the past but also as something that can be abstracted from the past and is happening now. Alexander arranges the ideas of the Enlightenment into a system for comparisons and suggests that there are three ideal types: radical, sceptical and liberal Enlightenments.

The papers in the forum debate of this issue provide an array of fresh perspectives and suggestions for how to investigate intellectual history. I am very pleased that the Journal of the Philosophy of History is able to offer this whole package for the reader's benefit and have no doubt that these papers will deepen our understanding of the foundations of intellectual history and conceptual change.

Jouni-Matti Kuukkanen

Editor-in-Chief 